\title{
A multicentre pharmacoepidemiological study of dermatological disorders in Wardha district
}

\author{
Anita H. Yuwnate ${ }^{1}$, Rakhamaji D. Chandane ${ }^{2}$, Kiran R. Giri ${ }^{1}$, Monica S. Yunati ${ }^{1}$, \\ Shyam S. Sirsam ${ }^{1}$
}

${ }^{1}$ Department of Pharmacology, Jawaharlal Nehru Medical College (DMIMS), Sawangi (Meghe), Dist. - Wardha, Maharashtra, India ${ }^{2}$ Department of Pharmacology, Govt. Medical College, Akola, Dist. - Akola, Maharashtra, India

Received: 8 September 2013 Accepted: 11 September 2013

*Correspondence to: Dr. Rakhamaji D. Chandane, Email:

drchandanerd@rediffmail.com

(C) 2013 Yuwnate AH et al. This is an open-access article distributed under the terms of the Creative Commons Attribution Non-Commercial License, which permits unrestricted non-commercial use, distribution, and reproduction in any medium, provided the original work is properly cited.

\begin{abstract}
Background: Skin diseases are common among the general population and account for a high percentage of all diseases. For considering the increase in the prevalence of specific skin diseases, prevalence data are needed. Appropriate treatment of common diseases and provision of essential drugs are two essential components of the primary health care. The aim in dermatological therapy is to use the safest and least number of drugs in order to obtain the best possible effect in the shortest period at reasonable cost. For that important step is taken to monitor, evaluate and therapeutically analyze the prescribing pattern of dermatological drugs.
\end{abstract}

Methods: 12210 cases were screened for dermatological disorders in the Primary Health Care Centers and Rural Hospital of Wardha district during the time frame 1st January 2006 to 30th September 2010, out of which 1000 patients experienced different variety of dermatological disorders were analyzed. In prescription analysis 800 prescriptions with 1946 drugs were analyzed.

Results: The prevalence of dermatological disorders in our study was found $8.19 \%$. Out of 1000 patients, there were 567 females $(56.7 \%)$ and 433 male (43.3\%).1000 cases were divided into five age groups viz. 1-20 yrs, 21-40 yrs, 41-60 yrs, 61-80 yrs and more than 80 yrs. Percentage distribution for the various age ranges were $21 \%, 48 \%, 20 \%, 8 \%$ and $3 \%$ respectively. In spectrum of dermatological disorders, Acne vulgaris $(14.8 \%)$ was the most common disorder followed by Tinea infection (13.6\%), Eczema (13.2\%), scabies $(12.4 \%)$ and pyoderma (11.6\%), Acute urticaria (6.6\%), Melasma (5.8\%), Psoriasis $(3.8 \%)$, Polymorphous light eruption (3.6\%), Phytophotodermatitis (2.6\%), Leprosy (2\%) and other disorders (10\%). The total number of drugs prescribed in 800 prescriptions was 1946 i.e. on average 2.43 drugs were prescribed per patient. Out of 1946 drugs, 1054 were topical and 892 were oral preparations. Antifungal was most common topically prescribed drug.

Conclusions: The prevalence of dermatological disorders is $8.19 \%$. Younger age group (21-40 yrs) and Females is most affected by dermatological disorders. The commonest dermatological disorder is Acne and in prescription analysis, antifungals are most commonly prescribed.

Keywords: Dermatological disorders, Prevalence, Prescription analysis

\section{INTRODUCTION}

Dermatological disorders are one of the most common disease presentations in the primary health care settings. But, unfortunately, their management is seldom routine. Each case may present distinct challenges in terms of diagnosis, treatment and overall patient care. Prevalence of dermatological disorders is more in India where customs, religions, languages, climate and socio-economic conditions vary across different parts of the country ${ }^{1}$
Dermatological problems exhibit broad spectrum of diagnosis ranging from purely cosmetic conditions to tumours and genetic to inflammatory disorders. ${ }^{2}$

Skin diseases are a major health problem affecting the prevalence of the population and causing agony and disability. ${ }^{3}$ There are probably at least 2000 different skin conditions that might present to the dermatologists. ${ }^{4}$ Treatment is helpful in curing the disease as well as in preventing the spread of communicable diseases. ${ }^{5}$ 
In clinical practice an epidemiological survey has various problems which include persistent changes in life style, population size, age distribution and the quality of health care services. ${ }^{6}$ Epidemiologic data are necessary for the monitoring of skin problems and provides the basis of training programs for medical professionals in primary health care with the aim to reduce long-term morbidity and socioeconomic impact. ${ }^{7}$

Prescribing drugs is an essential skill, which is required to be continuously assessed and refined accordingly. For improving utilization patterns, collection of data is an effective tool at hospital out-patient level. The pattern of drug use should be monitored to analyze the rationality, to increase the therapeutic benefits and reduce adverse effects. ${ }^{8}$ In health care delivery system, medical audit is used to oversee, monitor and analyze the medical treatment and suggest modification in prescribing practices of medical professionals which is useful in medical care. ${ }^{9}$

Keeping in view all the above mentioned facts, the present study was designed and carried out to evaluate the pharmacoepidemiological perspective of Dermatological disorders in Wardha District. This multicentric, cross-sectional, surveillance study is expected to benefit the individuals suffering from the physical, mental, social and, above all, emotional agony due to dermatological disorders.

\section{METHODS}

Study Design: Multicentric, Cross Sectional, Surveillance Study.

Locus of Study: 32 Health Care Centers of Wardha District:

1) Acharya Vinoba Bhave Rural Hospital ,Sawangi (Meghe) and Acharya Vinoba Bhave Grameen Rugnalaya Seloo (2 Health Care Centers).

2) Grameen Aarogya Kendra, Deoli, Shaskiya Grameen Rugnalaya, Seloo, Grameen Rugnalaya, Samudrapur and Grameen Rugnalaya, Karanja (4 Health Care Centers).

3) Prathamic Aarogya Kendra, Deoli, Mandgaon, Nandori, Zadsi, Salai(kala), Anji(Mothi), Kharangana (Morangana), Talegao, Allipur, Kangaon, Giroli, Gaul, Vijaygopal, Nachangaon, Rohana, Wayfad, Jalgaon, Aashti, Sahur, Girad, Burkoni, Kannamwargram, Kharangana (Gode), Hamadpur, Dahegaon and Sindi (Railway) (26 Health Care Centers).

\section{Methodology}

12210 cases were screened for dermatological disorders in the Primary Health Care Centers and Rural Hospital of Wardha district during the time frame $1^{\text {st }}$ January 2006 to $30^{\text {th }}$ September 2010, out of which 1000 patients experienced different variety of dermatological disorders were analyzed. The research protocol was approved by Institutional Ethics Committee.

1. Retrospective study of Case Sheets available in Medical Record Section of different Health Care Centers.

2. Interview of senior and junior health care professional.

3. Interview of patients suffering from dermatological disorders.

4. Monitoring and Evaluation :- The study included the following aspects:

i. Prevalence of Dermatological Disorders

ii. Age and sex Distribution

iii. Distribution or spectrum of dermatological disorder

iv. Treatment Modules

\section{RESULTS}

12210 cases were screened for dermatological disorders in primary health centers of study in a time frame of $1^{\text {st }}$ January 2006 to $30^{\text {th }}$ September 2010, out of which 1000 patients experienced different variety of dermatological disorders.

Prevalence: The prevalence of dermatological disorders in our study was found $8.19 \%$ during $1^{\text {st }}$ January 2006 to $30^{\text {th }}$ September 2010.

Sex distribution: Out of 1000 patients, there were 567 females $(56.7 \%)$ and 433 male (43.3\%). Dermatological disorders were seen more in females than in males (Figure 1).

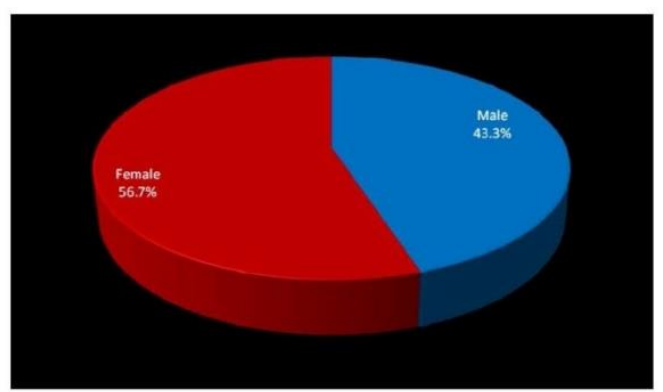

Figure 1: Sex distribution of dermatological disorders.

Age distribution: 1000 cases were divided into five age groups viz. 1-20 yrs, 21-40 yrs, 41-60yrs, 61-80yrs and more than 80 yrs. Percentage distribution for the various age ranges were $21 \%, 48 \%, 20 \%, 8 \%$ and $3 \%$ respectively. Dermatological diseases were seen more in 21-40 yrs age group (Figure 2).

\section{Spectrum of dermatological disorders}

Data collected from 1000 cases of dermatological disorders during the time frame $1^{\text {st }}$ January 2006 to $30^{\text {th }}$ September 2010 in the Primary Health Care Centers and Rural Hospital of Wardha district were analyzed critically. 


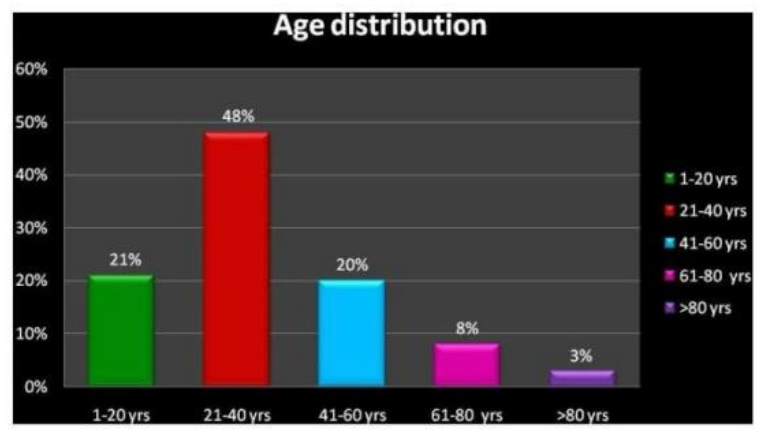

Figure 2: Age distribution of dermatological disorders.

In the study population, Acne vulgaris accounted for around 148 cases $(14.8 \%)$ was the most common disorder followed by Tinea infection 136 cases (13.6\%), Eczema 132 cases (13.2\%), scabies 124 cases (12.4\%) and pyoderma 116 cases $(11.6 \%)$. Acute urticaria accounted for around 66 cases $(6.6 \%)$ followed by Melasma 58 cases(5.8\%), Psoriasis 38 cases(3.8\%), Polymorphous light eruption 36 cases (3.6\%), Phytophotodermatitis 26 cases $(2.6 \%)$, Leprosy 20 cases $(2 \%)$ and other disorders 100 cases $(10 \%)$ (Table 1, Figure 3 ).

Table 1: Spectrum of dermatological disorders.

\begin{tabular}{|llll|}
\hline Sr. & $\begin{array}{l}\text { Dermatological } \\
\text { disorders }\end{array}$ & $\begin{array}{l}\text { Number } \\
\text { of Cases }\end{array}$ & Percentage \\
\hline 01 & Acne & 148 & $14.8 \%$ \\
\hline 02 & Tinea infection & 136 & $13.6 \%$ \\
\hline 03 & Eczema & 132 & $13.2 \%$ \\
\hline 04 & Scabies & 124 & $12.4 \%$ \\
\hline 05 & Pyoderma & 116 & $11.6 \%$ \\
\hline 06 & Acute urticaria & 66 & $6.6 \%$ \\
\hline 07 & Melasma & 58 & $5.8 \%$ \\
\hline 08 & Psoriasis & 38 & $3.8 \%$ \\
\hline 09 & PLE & 36 & $3.6 \%$ \\
\hline 10 & Phytophotodermatitis & 26 & $2.6 \%$ \\
\hline 11 & Leprosy & 20 & $2.0 \%$ \\
\hline 12 & Others & 100 & $10 \%$ \\
\hline & Total & 1000 & $100 \%$ \\
\hline
\end{tabular}

The other disorders included were Folliculitis, Angular cheilitis, Impetigo contagiosum, Pytriasis versicolor, Herper zoster, Insect bite reaction, Lupus vulgaris, Vitiligo, Alopecia, Onychomycosis, Palmar keratoderma, Solar melanosis, Lichen planus, Seborrheic dermatitis, Genital wart, Irritant contact dermatitis, Molluscum contagiosum, Herpes genital, Acanthosis nigricans,
Bullous pemphigoid, Drug reaction, Erythema Induratum, Darier's disease, Keratosis pilaris, Planter Keratoderma, Reiter's disease, Scrofuloderma, Mycetoma, Tropic ulcer, Cellulitis, Granuloma annulare, Kerion, Granulomatous disease, Discoid lupus erythromatosus (DLE) (Table 1, Figure 3).

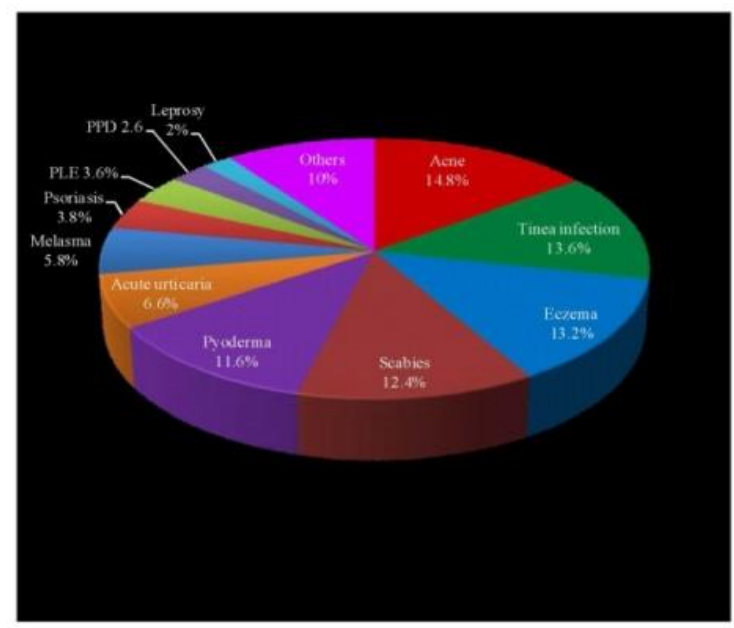

Figure 3: Spectrum of dermatological disorders in Study population.

\section{Prescription analysis (Table 2)}

The data was collected from prescriptions written in OPD. This included: age, sex, number of drugs, drug class, site of application, dose and frequency of application, duration of therapy.

Out of 1000 prescriptions 800 were finally selected for the analysis. The total number of drugs prescribed in 800 prescriptions was 1946 i.e. on average 2.43 drugs were prescribed per patient. Out of 1946 drugs, 1054 (54.16\%) were topical and $892(45.84 \%)$ were oral preparations.

Analysis of antifungal group revealed that out of 652 antifungal drugs (33.5\% of total drugs), 462 topical and 192 oral antifungal drugs are prescribed. Fluconazole was most commonly prescribed oral antifungal while clotrimazole was most common topically prescribed drug.

About 280 patients received at least one antihistaminic. 330 antibiotics $(16.95 \%)$ were prescribed in 266 prescriptions, out of which 40 had one topical and one oral antibiotic. Vitamins were mostly given with oral antibiotics.

Steroids were prescribed mostly in the topical form. Combination of one steroid with one antibiotic was prescribed in 24 out of 194 prescriptions of steroids. The miscellaneous category included NASIDs, antidandruff preparation etc. 
Table 2: Therapeutic agents prescribed in dermatological disorders.

\begin{tabular}{|c|c|c|c|c|c|}
\hline Class of Drugs & $\begin{array}{l}\text { Total No. of } \\
\text { Drug }(\%)\end{array}$ & Oral & Topical & Injection & Major therapeutic agents \\
\hline Antifungals & $652(33.5 \%)$ & 192 & 460 & - & $\begin{array}{l}\text { Clotrimazole, Fluconazole } \\
\text { Miconazole, Griseofulvin }\end{array}$ \\
\hline $\begin{array}{l}\text { Steroids and } \\
\text { combinations }\end{array}$ & $194(9.97 \%)$ & 10 & 184 & -- & Clobetasol, Betamethasone \\
\hline Antihistaminics & $304(15.62 \%)$ & 280 & 24 & -- & $\begin{array}{l}\text { Cetirizine, } \\
\text { Diphenhydramine, } \\
\text { Hydroxyzine, } \\
\text { Chlorpheniramine }\end{array}$ \\
\hline $\begin{array}{l}\text { Antiseptics } \\
\text { Antibiotics }\end{array}$ & $330(16.95 \%)$ & 266 & 64 & -- & $\begin{array}{l}\text { Minocycline, Erythromycin, } \\
\text { Azithromycin, Doxycycline }\end{array}$ \\
\hline Ectoparasiticides & $100(5.14 \%)$ & -- & 100 & -- & $\begin{array}{l}\text { Benzyl benzoate } \\
\text { Permethrin }\end{array}$ \\
\hline Vitamins & $96(4.93 \%)$ & 84 & 12 & -- & B- complex, Multivitamins \\
\hline Anti-Acne & $126(6.47 \%)$ & 26 & 100 & -- & Retinoid \\
\hline $\begin{array}{l}\text { Keratolytics and } \\
\text { Emollients }\end{array}$ & $80(4.11 \%)$ & -- & 80 & -- & Calamine lotion \\
\hline Anti-Herpes & $04(0.20 \%)$ & -- & 04 & -- & Acyclovir \\
\hline Miscellaneous & $60(3.08 \%)$ & 34 & 26 & -- & -- \\
\hline Total & $1946(100 \%)$ & $\begin{array}{l}892 \\
(45.84 \%)\end{array}$ & $\begin{array}{l}1054 \\
(54.16 \%)\end{array}$ & -- & \\
\hline
\end{tabular}

\section{DISCUSSION}

In most of the countries the prevalence of dermatological disorders is not well addressed. Also we do not know the exact magnitude of public health problem that can be attributed to dermatological disorders. For this reason, we decided to carry out this epidemiological survey. Many factors determine the pattern and prevalence of disorders in a given population such as age, gender, race, occupation, environment, diet etc.

The prevalence of skin diseases in general population has varied from $6.3 \%$ to $11.16 \%$ in various studies. ${ }^{10-14}$ Our finding of $8.19 \%$ fell within this range. We compared our prevalence rate of skin disorders with other studies done by Gangadharan et al. ${ }^{10}$ in Kerala (10\%), by Das et al. ${ }^{11}$ in Guwahati $(6.3 \%)$, by Devi et al. ${ }^{12}$ in Imphal $(6.56 \%)$, by Dayal et al. ${ }^{13}$ in Bundelkhand (8.59\%) and by Kuruvilla et al. ${ }^{14}$ in Dakshina Kannada (6.77\%).

Our study showed female preponderance which is similar to study by Kuruvilla et al..$^{14}$ while Dayal et al. ${ }^{13}$ reported an overall male preponderance for dermatological disorders.
Patients in age group 21-40 yrs formed the largest group of population affected by skin disorders in our study (48\%) (Figure 2). Kuruvilla et al. ${ }^{14}$ in Dakshina Kannada found the most common age group 10-29 yrs. with prevalence of $39.26 \%$. Grover et al. ${ }^{15}$ in rural Allahabad reported that patients in their second and third decades formed the largest group of population (50.7\%). The difference in prevalence rates can be attributed to differences in geographical locations, climatic conditions, industrialization, religious and cultural factors, literacy levels etc.

Our result showed that acne was the most common disorder with a prevalence rate of $14.8 \%$. Grover et al. in Allahabad ${ }^{15}$ reported that prevalence of acne was $17.7 \%$ but fungal infections were most common.

Fungal infection such as tinea infections were the second largest group of disorders in our study with prevalence rate of $13.6 \%$. This finding is similar to study carried out by Devi T, et al. ${ }^{12}$ at Imphal. Fungal infection was the most common disorder in most studies, varying in prevalence from $12.8 \%$ to $46.25 \%$. ${ }^{12-14,16,17}$ 
In our study, prevalence of Eczema was $13.2 \%$. Eczema has been reported as the $3^{\text {rd }}$ most prevalent dermatological disorder, the prevalence varying from $16.17 \%$ to $33.93 \% .{ }^{11-14,16,17}$ Our study reported a relatively less prevalence of eczemas as compared to other studies. Contact dermatitis was the commonest form of eczema.

The prevalence of scabies and pyoderma was $12.4 \%$ and $11.6 \%$ respectively. The prevalence was less in study done by Devi et al. ${ }^{12}$ High prevalence may be due to low socio-economic status and patients mostly belonging to rural areas. In studies conducted by Karanti et al. in Delhi ${ }^{18}$ and Sharma NL et al. in Himachal Pradesh ${ }^{19}$ too, these were the commonest dermatoses.

The cases of acute urticaria made up $6.6 \%$ of all skin diseases in this study, which is similar to that reported by Devi et al. from Imphal. ${ }^{12}$ Prevalence of Urticaria was found to be relatively higher as compared to that in study by Grover et al. conducted in Allahabad, ${ }^{15}$ by AKM et al. in Bangladesh ${ }^{20}$ and by Abdulrahman et al in Riyadh Military Hospital. ${ }^{21}$

The prevalence of Melasma (5.8\%) similar to study conducted by Grover et $\mathrm{al}^{15}$ and less in other studies. ${ }^{12,21}$ The prevalence of psoriasis $(3.8 \%)$ was more as compared to that of other studies. ${ }^{12,20,21}$

The prevalence of leprosy was only $2 \%$. This is similar to study conducted by Das et $\mathrm{al}^{11}$ and less in other studies. ${ }^{12,21}$ This may be due to the awareness of the people regarding this disease. Pyoderma and scabies were less prevalent in our study. The reason may be meticulous attention to body hygiene.

It was observed that 800 prescriptions carried 1946 drugs averaging 2.43 drugs per prescription. Maini $\mathrm{R}$ et al. ${ }^{22}$ found that in the dermatology department, the mean number of drugs per prescription was 2.6. It was also similar to study by Thawani et al $(2.26)^{23}$, W.M. Sweileh et al $(3.06)^{24}$ and Minocha et al in Ludhiana at tertiary hospital (3.36). ${ }^{25}$

Prescription analysis showed that antifungal drugs were the most commonly prescribed class of drugs followed by antibiotics, antihistaminics and steroids which is similar to the finding of W.M. Sweileh et al. ${ }^{24}$ In another study by Minocha et $\mathrm{al}^{25}$, antibiotics are more preferred than steroids and a study by Thawani et al, ${ }^{23}$ antihistaminics are more commonly prescribed. In our study, Topical preparations are more commonly prescribed than oral preparations similar to that of W.M. Sweileh et $\mathrm{al}^{24}$ and by Minocha et al. ${ }^{25}$

In our study, Fluconazole was most commonly prescribed oral antifungal similar to that of in Indian tertiary hospital. ${ }^{25}$ It may be because of its weekly dose and less possibility of side effects. Steroids were prescribed mostly in the topical form. The systemic use of antibiotics was preferred to the topical use as similar in another studies. $^{24,25}$

Finally our study concludes that the prevalence of dermatological disorders in rural as well as urban population of Wardha District is $8.19 \%$. Younger age group (21-40 yrs) is most affected by dermatological disorders. Dermatological problems are more common in females in comparison to males. The commonest dermatological disorder is Acne followed by Tinea infection, Eczema, Scabies and Pyoderma. In prescription analysis, antifungals are most commonly prescribed followed by antibiotics, antihistaminics and steroids. Further studies also needed to be carried out to cover private health sector for more complete picture of dermatological disorders.

\section{ACKNOWLEDGEMENTS}

We are thankful to Dr. R. K. Jha, Professor \& Head, Dept. of Pharmacology, Jawaharlal Nehru Medical College, Sawangi (Meghe) Wardha, for his valuable guidance and help to carry out this study.

\section{Funding: None \\ Conflict of interest: None declared \\ Ethical approval: The study was approved by the Institutional Ethics Committee}

\section{REFERENCES}

1. Mehta TK. Pattern of skin diseases in India. Indian J Dermatol Venereol Leprol. 1962; 28:134-9.

2. Boi S, Cristofolini M, Micciolo R, Polla E and Palma PD. Epidemiology of Skin Tumors: Data from the Cutaneous Cancer Registry in Trentino, Italy. Journal of Cutaneous Medicine and Surgery: Incorporating Medical and Surgical Dermatology. 2003; 7(4): 300-305.

3. Khalifa KA, Hadithi TS, Lami FH and Diwan JK. Prevalence of skin disorders among primary-school children in Baghdad governorate, Iraq. Eastern Mediterranean Health Journal. 2010: 209-213.

4. Zamanian A, Mahjub H. Prevalence of Skin Diseases in Hamedan, Iran in 2002, Indian J Dermatol 2005; 50(4): 208-211.

5. Azam JS. Spectrum of skin disorders presenting to King Abdul Aziz Hospital during Hajj season-2000. J Ayub Med Coll Abottabad. 2004;16(3):10-3.

6. Najdawi F, Fa'ouri M. Frequency and types of skin disorders and associated diabetes mellitus in elderly Jordanians. Eastern Mediterranean Health Journal. 2002; 8(4-5): 574- 8.

7. Minas M, Koukosias N, Zintzaras E, Kostikas K, and Gourgoulianis KI. Prevalence of chronic diseases and morbidity in primary health care in central Greece: An epidemiological study. BMC Health Serv Res. 2010; 10: 252.

8. Henricson K, Stenberg P, Rametsteiner G, Ranstam J, Bertil S, Melander HA. Socioeconomic factors, 
morbidity and drug utilization - an ecological study. Pharmacoepidemiology and Drug Safety. 1998; 7(4): 261-267.

9. Sarkar C, Das B, Sripathi H .Drug prescribing pattern in dermatology in a teaching hospital in western Nepal. Journal of Nepal Medical Association. 2001;41:241-246.

10. Gangadharan C, Joseph A, Sarojini PA. Pattern of skin diseases in Kerala. Indian J Dermatol Venereol leprol. 1976;42:49-51.

11. Das KK. Pattern of dermatological diseases in Guwahati Medical College and Hospital Guwahati. Indian J Dermatol Venereol Leprol. 2003;69:16-8.

12. Devi T, Zamzachin G. Pattern of skin diseases in Imphal. Indian J Dermatol. 2006;51:149-50.

13. Dayal SG, Gupta GP. A cross section of skin diseases in Bundelkhand region, UP. Indian $\mathrm{J}$ Dermatol Venereol Leprol. 1977;43:258-61.

14. Kuruvilla M, Sridhar KS, Kumar P, Rao G. Pattern of skin diseases in Bantwal Taluq, Dakshina Kannada. Indian J Dermatol Venereol Leprol. 2000;66:247-8.

15. Grover S, Ranyal RK, and Bedi MK. A cross section of skin diseases in rural Allahabad, Indian $\mathbf{J}$ Dermatol. 2008; 53(4): 179-181.

16. Jaiswal AK, Singh G. Pattern of skin diseases in Kashmir region of India. Indian $\mathrm{J}$ Dermatol Venereol Leprol. 1999; 65: 258-60.

17. Nair SP, Nair TVG. Pattern of dermatological diseases in Trivendrum. Indian J Dermatol Venereol Leprol. 1999; 65:261-3.
18. Karanti BK. Pattern of skin diseases in a semi-urban community of Delhi. Indian J Dermatol Venereol Leprol. 1984; 50: 213-4.

19. Sharma NL, Sharma RC. Prevalence of dermatological diseases in school children of a high altitude tribal area of Himachal Pradesh. Indian J Dermatol Venereol leprol. 1990; 56: 375-6.

20. Shariful Islam AKM, Wadud MA. Skin diseases in a rural area of Bangladesh. Bangladesh J Dermatol Venereol Leprol. 1999;16:36-39.

21. Abdulrahman Y.AI-Zoman 'Facharizt, Abdulrahman K.AI-Asmari. Pattern of skin diseases at Riyadh Military Hospital, Egyptian Dermatology Online Journal 2008; 4(2): 1-10.

22. Maini R. Drug utilization study in dermatology in a tertiary hospital in Delhi. Indian Journal of Physiology and pharmacology. 2002;46(1):107-10.

23. Thawani VR, Motghare VM, Dani AD and Shelgaokar SD. Therapeutic audit of dermatological prescription. Ind. J Dermatol. 1995:40(1):13-19.

24. Sweileh WM. Audit of prescribing practices of topical corticosteroids in outpatient dermatology clinics in north Palestine. Eastern Mediterranean Health Journal. 2006;12(1):161-169.

25. Minocha KB, Bajaj S, Gupta K. A clinicopharmacological study of out patient prescribing pattern of dermatological drugs in Indian tertiary Hospital. Indian J Pharmacol 2002;32:384-5.

doi:10.5455/2319-2003.ijbcp20131215

Cite this article as: Yuwnate AH, Chandane RD, Giri

KR, Yunati MS, Sirsam SS. A multicentre

pharmacoepidemiological study of dermatological

disorders in Wardha district. Int J Basic Clin

Pharmacol 2013;2:751-6. 